\title{
Digital, Privacidade e Proteção de Dados: uma análise dos impactos da LGPD no Direito do Trabalho
}

\author{
Digital Society, Privacy and Data Protection: an analysis of the impacts of the \\ LGPD on labor law
}

Vanessa Rocha Ferreira ${ }^{1}$, Beatriz Normando Falcão, Lucas Jorge João Bizzocchi

RESUMO

O estudo tem como objetivo a análise das alterações no âmbito laboral brasileiro frente à entrada em vigor da Lei Geral de Proteção de Dados Pessoais (LGPD), perpassando os motivos que ensejam a necessidade de elaboração de uma política voltada para a proteção de tais informações, debatendo a situação de pandemia da Covid-19 e a ascensão do teletrabalho. A pesquisa busca elucidar os impactos trazidos com o advento da referida legislação e as respectivas consequências tanto para o campo obrigacional do empregador quanto para a esfera de direitos do empregado, ao passo que se observa como tais novidades acompanham as rápidas mudanças observadas nas relações trabalhistas.

Palavras-chave: LGPD; Dados; Empregado.

\begin{abstract}
The study aims to analyze the changes in the Brazilian labor environment in view of the entry into force of the General Law for the Protection of Personal Data (LGPD), covering the reasons that led to the need to develop a policy aimed at protecting this information, putting in debate the situation of the Covid-19 pandemic and the rise of teleworking. The research seeks to elucidate the impacts brought about by the advent of the aforementioned legislation and the respective consequences for both the employer's obligatory field and the sphere of employee rights, while observing how such novelties accompany the rapid changes observed in labor relations.
\end{abstract}

Keywords: Work; LGPD; Data; Employee.

${ }^{1}$ Centro Universitário do Estado do Pará (CESUPA).

E-mail: vanessarochaf@gmail.com. 


\section{INTRODUÇÃO}

A presente pesquisa parte da publicação da Lei Geral de Proteção de Dados Pessoais (LGPD), Lei Federal no 13.709, de 14 de agosto de 2018, a qual, em termos gerais, dispõe sobre a proteção de dados pessoais em toda a esfera nacional.

Em resumo, a LGPD foi criada em resposta às atuais demandas de mercado em um Brasil fortemente marcado pela globalização, com o objetivo de regulamentar o tratamento de dados pessoais pelas empresas, uma vez que estes ganham cada vez mais importância no âmbito econômico, sendo possível, por meio deles, fazer predições, analisar perfis de consumo, opinião dos consumidores, grupos alvos, entre outras atividades. Nesse cenário, tem-se que atualmente, países ao redor de todo o globo já possuem leis para a proteção de dados pessoais, visando à regulamentação do tratamento de dados pelas empresas, bem como a responsabilização destas em caso de mau uso de tais informações, buscando garantir a total proteção aos Direitos Fundamentais à Liberdade e à Privacidade de indivíduos.

Ocorre que, o referido instrumento possui um diferencial em relação às demais normas que regulam a proteção individual da vida privada, o qual se baseia na amplitude de aplicação da Lei, pois traz os princípios que a regem e os objetivos a serem alcançados, destacando com precisão os tipos de dados pessoais a serem defendidos (criando, inclusive, novas classificações), seus titulares e os direitos a que estes podem reclamar em caso de possíveis violações aos ditames da norma. Ademais, a referida regulamentação delimita de forma clara os alcances territoriais de proteção, diretrizes de fiscalização e responsabilidade a ser atribuída aos agentes de tratamento de dados, sendo norma mais completa que àquela que inspirou sua criação (a Lei europeia de proteção denominada General Data Protection Regulation - GDPR). Consequentemente, a LGPD causa impactos significativos no Direito do Trabalho e nas relações trabalhistas como um todo, com enfoque nas obrigações do empregador (empresa) e os direitos do empregado (trabalhador).

Nota-se, em um primeiro momento, que seria razoável deduzir que o novo regulamento se encontra conectado diretamente somente às áreas do Direito Empresarial ou Direito do Consumidor. No entanto, o que se busca elucidar na presente pesquisa é que a LGPD possui nexo de aplicação direto com as relações de trabalho e logicamente com o Direito Trabalhista. 
Desse modo, esse estudo se baseia na análise de aplicação da LGPD nas relações de trabalho e os consequentes reflexos que norteiam as relações marcadas pelos agentes em embate: empregadores X empregados.

Metodologicamente, faz-se um estudo teórico-normativo, por meio de pesquisa bibliográfica, doutrinária e documental nas mais diversas esferas de prestação de serviços. Para tanto, busca-se demonstrar a fragilidade da proteção à privacidade do trabalhador, perpassando pelo contexto histórico brasileiro relativo ao tema. Posteriormente, dá-se enfoque, ao cenário pandêmico, com a adoção em massa da modalidade de trabalho home office. Por fim, serão feitos breves esclarecimentos acerca das possíveis exigências a serem aplicadas ao detentor dos dados pessoais alheios, em caso de má gestão das informações a ele confiadas.

\section{O SURGIMENTO DA LGPD E A NECESSIDADE DE PROTEÇÃo À PRIVACIDADE}

Observa-se que a LGPD possuía campo fértil para se estabelecer, ao passo que o Sistema Jurídico brasileiro se encontrava em limbo quanto a tal temática de proteção de dados, mesmo se deparando com a imersão, quase que completa, de grande parte do meio populacional nas plataformas digitais, transformando as relações pessoais e afetando diretamente a maneira como a sociedade vislumbra o conceito de privacidade.

Conforme já elucidado, a LGPD surgiu exatamente pela necessidade de o Poder Judiciário brasileiro preencher essa lacuna jurídica, uma vez que a proteção do disponibilizador de dados, em meio virtual, restava prejudicada em face da facilidade de reconhecimento de dados. Nesse contexto, o cenário anterior à vigência da Lei $\mathrm{n}^{\circ}$ $13.709 / 2018^{2}$ era marcado pelo uso de plataformas digitais como meios para a prestação de serviços e lazer, os quais exigiam de seus usuários informações pessoais cuja privacidade não era respeitada.

De forma esquematizada, com a Revolução Tecnológica 4.0, chamada de Quarta Revolução Industrial, cada indivíduo, na medida de sua imersão digital, seja pelas redes sociais, na busca por lazer, ou no sistema interno de uma empresa a qual é vinculado,

\footnotetext{
${ }^{2}$ BRASIL. Lei no 13.709, de 14 de julho de 2018. Lei Geral de Proteção de Dados Pessoais (LGPD). Brasília, DF, Disponível em: http://www.planalto.gov.br/ccivil_03/_ato2015-2018/2018/lei/113709.htm. Acesso em: 10 jan. 2022.
} 
deixa obrigatoriamente dados que podem ser visualizados a qualquer tempo por terceiros (sejam amigos em redes sociais, colegas de trabalho, empregadores ou, até mesmo, empresas atuantes em diversos setores e Órgãos Governamentais) ${ }^{3}$.

Logo, o que vem a ser tratado com a promulgação da Lei é a possibilidade de se exigir, ou não, uma proteção completa e absoluta das informações disponibilizadas nas plataformas virtuais e, se houver, de que forma seria possível realizá-la. Da mesma forma, questiona-se também a possibilidade de haver uma disponibilização ampla e ilimitada de todo e qualquer dado gerado online a um terceiro, que assim entenda ser de seu interesse. Denota-se que esta questão perpassa pelas noções do embate clássico existente no Judiciário, envolvendo o Direito à Liberdade e o Direito à Privacidade.

Ao adentrar mais a fundo na presente temática, destaca-se que, tanto a liberdade, quanto a privacidade, não são conceitos absolutos no ordenamento jurídico brasileiro. Observa-se que, ao tratar da proteção de dados em um contexto geral, torna-se clara a necessidade de relativização do Direito à Liberdade, com o objetivo de priorizar a proteção ao Direito à Intimidade, Privacidade, Honra e Imagem. De igual forma, resta inegável que o Princípio da Transparência também não poderá se sobrepor ao Princípio da Vida Privada, o que se demonstra efetivamente com o surgimento da LGPD.

Historicamente, assim entendem Vicente Vasconcelos Coni Junior e Rodolfo Pamplona Filho (2021, p. 6)

De fato, a proteção jurídica do direito à privacidade/intimidade até determinado momento histórico se mostrava em alguma medida suficiente, mas hoje com o desenvolvimento da informática, armazenam-se um número ilimitado de dados de todas as naturezas, os quais circulam entre Estados, particulares e empresas privadas, muitas vezes sem qualquer tipo de controle, fica clara a necessidade de maior proteção.

No entanto, com o passar das décadas, as relações interpessoais foram atravessadas pelo ambiente virtual e, consequentemente, pela rapidez de informações e dados disponibilizados para consultas. Como reflexo, a busca pelo resguardo aos Direitos Fundamentais relativos à Privacidade passa a ganhar escopo no meio jurídico.

\footnotetext{
${ }^{3}$ BLUM, Renato Opice; WAJSBROT, Shirly. A proteção de dados no Brasil 4.0. 2020. Disponível em: https://institutoibde.com.br/2020/06/26/a-protecao-de-dados-no-brasil-4-0/. Acesso em: 22 jan. 2022.

${ }^{4}$ CONI JUNIOR, Vicente Vasconcelos; PAMPLONA FILHO, Rodolfo. A Lei Geral de Proteção de Dados e seus reflexos nas relações jurídicas trabalhistas. 2021. Disponível em: https://revistas.unifacs.br/index.php/redu/article/view/7060. Acesso em: 16 jan. 2022.
} 
Acerca do assunto, Fernando Cantelmo ${ }^{5}$ afirma:

Deste modo, nesta dicotomia, decerto que os Direitos Pessoais e/ou Individuais devem se sobrepor aos Direitos Institucionais, do mesmo modo que o Direito Privado deve ter prioridade sobre o Direito Público. Esta certeza de que os direitos personalíssimos devem se sobrepor ao princípio da transparência e congêneres possui fundamentação não apenas nas mais variadas legislações civilistas brasileiras, mas também nos exemplos trazidos pelo próprio Estado, pelo Governo Federal e órgãos de Estado, bem como nos dispositivos que impõem os fundamentos da Constituição Federal Brasileira de 1988.

Observa-se ainda que, em cenário pré-LGPD, a realidade por trás do uso de ferramentas perpassava por um errôneo sentimento de liberdade geral para com as informações que ali constavam, reforçando a ideia da internet como "terra sem lei", não havendo rigor na proteção à privacidade. Nesse sentido, anteriormente ao ano de 2018 no Brasil, não existia um instrumento normativo de diretrizes gerais para a proteção de dados. Importante ressaltar que, apesar de o tema ter ganhado popularidade em anos recentes, a temática já é debatida há anos, tendo como precursores países europeus ainda nas décadas de 1970 e 1980, tendo sido editada a primeira lei voltada ao assunto em Hessen, na Alemanha, introduzindo assim, pela primeira vez no cenário jurídico o conceito de proteção de dados, e servindo como base para países como França, Noruega e Suécia ${ }^{6}$.

No âmbito nacional, é notável o longo caminho percorrido até a vigência da atual Lei Geral de Proteção de Dados Pessoais, visto que, antes da entrada da mesma em vigor, o Poder Legislativo já havia se manifestado em casos pontuais acerca do Direito à Proteção da Intimidade em meios virtuais, sendo este o enfoque de proteção pretendido pela LGPD.

Para comprovar tal afirmativa, faz-se um adendo às principais normas que fundamentam a criação de uma norma mais específica que tutelasse os dados pessoais.

A exemplo do interesse no judiciário de tutelar as questões referentes à proteção de dados, tem-se que, em 1988, com a Constituição Federal, o texto incorporado ao seu

\footnotetext{
${ }^{5}$ CANTELMO, Fernando. A Lei Geral de Proteção de Dados e o conflito entre direito de privacidade versus direito de informação e publicidade dos atos públicos: noções legais sobre divergências constitucionais consolidadas pela lgpd. Noções legais sobre divergências constitucionais consolidadas pela LGPD. 2021. Disponível em: https://jus.com.br/artigos/92061/a-lei-geral-de-protecao-de-dados-e-oconflito-entre-direito-de-privacidade-versus-direito-de-informacao-e-publicidade-dos-atos-publicos. Acesso em: 19 jan. 2022.

${ }^{6}$ MACIEL, Rafael Fernandes. Manual Prático sobre a Lei Geral de Proteção de Dados Pessoais (Lei $\mathbf{n}^{\mathbf{0}}$ 13.709/18). RM Digital Education. $1^{\text {a }}$ Edição. Goiânia - GO. 2019.
} 
art. $5^{\circ}$, referente aos direitos e deveres dos cidadãos, passou a tratar, ainda de que de forma geral, da privacidade dos brasileiros, ao fundamento de que determina serem invioláveis a intimidade, a vida privada, a honra e a imagem das pessoas, assegurado o direito a indenização pelo dano material ou moral decorrente de sua violação ${ }^{7}$.

Como desdobramento do texto constitucional, novas leis e determinações abordaram complementarmente os moldes do Direito à Privacidade, a exemplo da Lei 9.296 de $1996^{8}$, que determina a inviolabilidade do sigilo das correspondências e das comunicações telegráficas, de dados e das comunicações telefônicas, salvo, no último caso, por ordem judicial, nas hipóteses e na forma que a lei estabelecer para fins de investigação criminal ou instrução processual penal.

Nessa mesma linha, o Código de Defesa do Consumidor, Lei 8.078/1990, desenvolveu as relações entre empresas e clientes, dedicando uma seção especifica para cadastros e bancos de dados (seção VI) e em seu texto defende o direito de o consumidor acessar os dados que uma empresa tem sobre ele e solicitar sua correção, caso alguma informação esteja incorreta (art. 43, caput e parágrafo $3^{\circ}$ ).

Já no ano de 2014, criou-se o Marco Civil da Internet, Lei ${ }^{\circ} 12.965^{10}$, sendo este um dos mais inovadores elementos normativos que existem até hoje no Brasil, tutelando o uso da internet no país, prevendo princípios, garantias, direitos e deveres para quem usa a rede, bem como a determinação de diretrizes para a atuação do Estado, reforçando o Direito à Privacidade.

Mais um exemplo emblemático é a Lei $\mathrm{n}^{\mathrm{o}} 12.737 / 2012^{11}$, conhecida como Lei Carolina Dieckmann, criada para criminalizar a invasão de aparelhos eletrônicos visando à obtenção de dados pessoais, a exemplo de fotos intimas (com ocorreu no caso envolvendo a atriz que dá nome à Lei).

Em resumo, a LGPD passou a vigorar em todo território nacional em 18 de setembro de 2020, restando pendentes apenas os artigos relacionados às sanções

\footnotetext{
${ }^{7}$ MACIEL BRASIL. Constituição (1988). Constituição Federal, de 1988. Brasília, DF, 1988. Disponível em: http://www.planalto.gov.br/ccivil_03/constituicao/constituicao.htm. Acesso em: 10 jan. 2022.

${ }^{8}$ BRASIL. Lei $\mathbf{n}^{\mathbf{0}}$ 9.296, de 24 de julho de 1996. Brasília, Disponível em: http://www.planalto.gov.br/ccivil_03/leis/19296.htm. Acesso em: 05 jan. 2022.

${ }^{9}$ BRASIL. Lei $\mathbf{n}^{\mathbf{0}} \mathbf{8 . 0 7 8}$, de 1990. Brasília. Disponível em: http://www.planalto.gov.br/ccivil_03/leis/18078compilado.htm. Acesso em: 05 jan. 2022

${ }^{10}$ BRASIL. Lei $\mathbf{n}^{\mathbf{0}} \mathbf{1 2 . 9 6 5}$, de 2014. Brasília, Disponível em: http://www.planalto.gov.br/ccivil_03/_ato2011-2014/2014/lei/112965.htm. Acesso em: 07 jan. 2022.

${ }^{11}$ BRASIL. Lei $\mathbf{n}^{\mathbf{0}}$ 12.737, de 2012. Lei Carolina Dieckman. Disponível em: http://www.planalto.gov.br/ccivil_03/_ato2011-2014/2012/lei/112737.htm. Acesso em: 20 jan. 2022.
} 
administrativas para aqueles que desrespeitarem as normas de tratamento de dados pessoais. A referida Lei, em conformidade com seu art. $3^{\circ}$, se aplica a toda pessoa natural ou jurídica, de direito público ou privado, visando garantir a proteção dos direitos fundamentais de privacidade, liberdade e personalidade da pessoa natural, e necessariamente precisa ser observada pela União, Estados, Distrito Federal e municípios, em relação às normas gerais, e surge como freio aos atos de invasão de dados, visando garantir uma maior evidência do Direito à Privacidade nos meios virtuais.

Por outro lado, importante citar que a norma, segundo seu art. $4^{\circ}$, não é aplicável ao tratamento de dados pessoais realizado por pessoa natural para fins particulares e não econômicos, ou para fins exclusivamente jornalísticos, artísticos ou acadêmicos. Em mesma linha, também é inaplicável para fins de segurança pública, defesa nacional e segurança do Estado ou atividades de investigação e repressão de infrações penais ou provenientes de fora do território nacional e que não sejam objeto de comunicação, uso compartilhado de dados com agentes de tratamento brasileiros ou transferência internacional com outro país que não o de proveniência, desde que este proporcione grau de proteção de dados pessoais adequado ao previsto.

Assim sendo, partindo dos pressupostos já citados, é necessário entender quais os tipos de dados e informações que a Lei visa à proteção. A resposta a tal questionamento se baseia nos conceitos trazidos pelo art. $5^{\circ}$, I da própria norma. Por tal definição, tem-se dado pessoal como todo aquele relacionado à pessoa natural identificada ou identificável. Em termos mais acessíveis, dados pessoais são todos aqueles que podem identificar uma pessoa, tais como, números únicos identificáveis ( $\mathrm{RG}, \mathrm{CPF}, \mathrm{CNH})$, características pessoais (nome e endereço, exames médicos, hábitos de consumo), entre outros. Tais informações, por conseguinte, dentro das empresas que as recolheram, serão alvo do processo de tratamento de dados pessoais, sendo este realizado para qualquer operação feita com o uso dessas informações, que se revelam em 20 verbos de ação previstos na LGPD, em rol exemplificativo.

Observa-se o art. $5^{\circ}, \mathrm{X}^{12}$ :

Tratamento de dados é toda operação realizada com dados pessoais, como as que se referem a coleta, produção, recepção, classificação, utilização, acesso, reprodução, transmissão, distribuição, processamento, arquivamento, armazenamento, eliminação, avaliação

\footnotetext{
${ }^{12}$ BRASIL. Lei no 13.709, de 14 de julho de 2018. Lei Geral de Proteção de Dados Pessoais (LGPD). Brasília, DF, Disponível em: http://www.planalto.gov.br/ccivil_03/_ato2015-2018/2018/lei/113709.htm. Acesso em: 10 jan. 2022.
} 
ou controle da informação, modificação, comunicação, transferência, difusão ou extração.

Ademais, a Lei também cria novas classificações com o objetivo de categorizar tais dados a serem protegidos.

Em sendo assim, é válido determinar que dados conceituados como sensíveis, no art. $5^{\circ}$, II, são aqueles possuidores de informações que, caindo em mãos alheias, podem ser usadas com intuito de discriminar o indivíduo, a exemplo de dados relacionados à raça, religião, política, questões de saúde ou vida sexual, carecendo de proteção especial, visando a integridade da pessoa natural no ambiente de trabalho.

A segunda classificação para os dados pessoais, que recebe regulação específica, é aquela à qual faz menção a crianças e adolescentes, cujo tratamento só poderá ser realizado com o consentimento especifico de, pelo menos, um dos pais ou responsáveis legais do mesmo, de acordo com o art. 14, parágrafo $1^{\circ}$, da LGPD. Nesse sentido, o controlador (figura que será mais aprofundada em tópico a seguir) deverá realizar todos os esforços razoáveis para verificar que o consentimento a que se refere o parágrafo $1^{\circ}$, do artigo supracitado, foi dado pelo responsável pela criança, consideradas as tecnologias disponíveis, vide art. 14, §5º LGPD.

Por fim, tem-se os chamados dados anonimizados, relativos à titular que não possa ser identificado, considerando a utilização de meios técnicos razoáveis e disponíveis na ocasião de seu tratamento, conforme determinado pelo art. $5^{\circ}$, III, LGPD. Desta forma, estariam fora do escopo de aplicação da Lei, à exceção se o processo de anonimização puder ser revertido ou se estes forem utilizados na formação de perfis comportamentais.

Quanto aos principais objetivos da Lei Geral de Proteção de Dados Pessoais, uma vez que a finalidade da mesma é proteger liberdades e Direitos Fundamentais, estes estão ligados à segurança jurídica em sua essência, fortalecendo as relações jurídicas e à confiança do titular no procedimento, e a transparência ao longo do processo de coleta, armazenamento e uso de dados, visando proteger a privacidade dos indivíduos, por meio da padronização das formas de todas as etapas envolvidas no processo em questão, por meio de um regramento harmônico, ao mesmo tempo em que fomenta o desenvolvimento econômico e tecnológico, e favorece a concorrência.

Observa-se que, as leis anteriormente introduzidas no ordenamento e as determinações de cada artigo supracitado se complementam. Tais objetivos se alinham harmonicamente com o intuito de priorizar a boa-fé, a finalidade, adequação, necessidade, o livre acesso, a qualidade de dados, a transparência, a segurança, a prevenção, a não 
discriminação, e a responsabilização e prestação de contas. Esses objetivos que se encontram expressamente determinados como os Princípios norteadores da Lei, descritos em seu art. $6^{\circ}$. No entanto, a tutela efetiva de tais Direitos e Princípios pretendidos depende, essencialmente, de autoridade de proteção de dados independente e com corpo técnico qualificado capaz de aplicar e interpretar a lei de modo equilibrado.

Em resumo, tem-se que a realidade por trás da promulgação da Lei Geral de Proteção de Dados (LGPD) nada mais é do que a efetivação concreta dos moldes de proteção à privacidade em meio virtuais que as leis citadas no início do tópico visavam tutelar. Cada artigo da Lei é fundamental para nortear a forma como a exposição de dados pessoais e informações poderá se manter e garantir a proteção integral de Direitos Fundamentais, tais como o Direito à Privacidade e à Intimidade do usuário.

\section{A LGPD E A PROTEÇÃO À PRIVACIDADE DO TRABALHADOR: OS REFLEXOS DA NORMA NA ESFERA LABORAL}

Com base em suas características gerais e amplitude, a LGPD abarca as mais diversas relações interpessoais que perpassem, em todos os graus, pelos meios virtuais, e em relação ao Direito do Trabalho, não poderia ser diferente.

Na esfera trabalhista, observa-se que a explosão do uso de plataformas virtuais na prestação de serviços acompanhou o movimento de vistoria por parte do empregador no manejo das ferramentas tecnológicas utilizadas pelo empregado na realização de sua função. Veja-se que, no início do uso das ferramentas tecnológicas, sejam elas computadores, sistemas internos, smartphones, criou-se um errôneo entendimento de que, uma vez que o obreiro presta um serviço por meio de uma plataforma - a qual exige o fornecimento de determinado dado -, o empregador detentor daquela atividade a ser desenvolvida também seria o detentor dos dados.

Em uma análise primordial, tal afirmativa parece correta, mas existem ressalvas.

No cenário antecessor à promulgação da Lei, empresas com alta demanda e mão de obra já atravessada pelas plataformas digitais na prestação de seus serviços, acabavam por vistoriar eletronicamente seus funcionários. A ação aqui descrita possui o conceito de "Fiscalização por Algoritmo", termo inovador nas relações trabalhistas, o qual é 
exemplificado nas relações de trabalho por Caroline Marchi e Fernanda Assalin (2021, p. 1) da seguinte forma ${ }^{13}$ :

Existem diversos exemplos do uso de algoritmos nas relações de trabalho, como a revisão automática de currículos de candidatos a emprego ou monitoramento das atividades dos empregados segundo metas de produtividade estabelecidas pela empresa para fins de premiação ou dispensa.

Assim, adveio a Lei 13.709/2018, dando palco para debate acalorado, ao fundamento de que, ao mesmo tempo em que esta protege a privacidade dos indivíduos, também molda e gera clara possibilidade de armazenamento de dados por parte de terceiros, sejam estas empresas, empregadores, ou até mesmo sistemas digitais voltados especificamente para o armazenamento de informações.

Conforme elucidado, a LGPD criou uma esfera de proteção ao usuário virtual. Ocorre que, com a Revolução Tecnológica 4.0, o uso das plataformas virtuais na prestação de serviços se tornou muito usual, principalmente no que diz respeito à prestação de serviços por trabalhadores, o que também gera necessidade de disponibilização de dados e uma possível violação à intimidade do trabalhador.

Mas a questão inquietante é a seguinte: como a vigência da LGPD impacta as relações trabalhistas?

A resposta requer uma análise ponto a ponto da norma, conforme feito no tópico anterior, mas se traduz no fato de que o intuito da Lei é assegurar a privacidade dos indivíduos em todos os setores da economia; logo, como consequência, estaria o âmbito trabalhista inevitavelmente por ela atingido. Nesse sentido, em um contrato de trabalho é possível identificar inúmeros dados pessoais coletados pelo empregador a respeito da pessoa a ser contratada, requisito básico para a consolidação de uma relação de emprego, sendo tais dados, em sua essência, inacessíveis a terceiros, pela natureza sigilosa que ostentam.

A LGPD surge como um instrumento de autodeterminação da pessoa natural que cede seus dados pessoais, dando a ela um conjunto de direitos, que juntos, dão ao indivíduo a possibilidade de estabelecer uma relação pautada na transparência com o

\footnotetext{
${ }^{13}$ MARCHI, Caroline; ASSALIN, Fernanda Pellegrino Gianotti. Implicações dos algoritmos nas relações de trabalho após a LGPD. 2021. Disponível em: https://www.machadomeyer.com.br/pt/inteligenciajuridica/publicacoes-ij/trabalhista-ij/implicacoes-dos-algoritmos-nas-relacoes-de-trabalho-apos-a-lgpd. Acesso em: 23 jan. 2022.
} 
responsável pelo controle dos dados em questão, tendo certo controle quanto à destinação a ser dada as suas informações pessoais.

Nesse contexto, é importante frisar que, os titulares dos dados pessoais conceituados como toda a pessoa natural a quem se referem os dados pessoais que são objeto de tratamento, vide art. $5^{\circ}, \mathrm{V}$ da Lei 13.709 -, tiveram seus direitos ampliados pela Lei e devem ser garantidos de forma acessível e eficaz, de acordo com o disposto no corpo do art. 18 da norma.

Em sendo assim, alguns dos principais direitos agora garantidos são atravessados pela confirmação da existência de tratamento de dados pessoais; acesso aos dados pessoais; correção de dados pessoais incompletos, inexatos ou desatualizados; anonimização, bloqueio ou eliminação de dados pessoais desnecessários, excessivos ou tratados em desconformidade com a LGPD; portabilidade de dados pessoais a outro fornecedor de produto ou serviço; eliminação de dados tratados com o seu consentimento; obtenção de informações sobre as entidades públicas e privadas, com as quais o controlador realizou o compartilhamento de dados pessoais; obtenção de informações sobre a possibilidade de não consentir com o tratamento de dados pessoais e sobre as consequências da negativa; revogação do consentimento dado para o tratamento de dados pessoais e portabilidade dos dados, todos estes descritos em rol do art. 18, Lei. Devido a sua natureza, este novo rol de Direitos tem sido encarado como um forte elemento de competição entre diferentes empresas que oferecem serviços similares baseados no uso de dados pessoais.

Nesse sentido, entende-se que, em todas as etapas envolvidas em uma relação de trabalho, faz-se necessário o tratamento de dados pessoais, e isso ocorre desde o momento do anúncio da vaga até a rescisão contratual de um trabalhador. Em reflexo, a LGPD e todos os seus ditames são aplicáveis a todo e qualquer tipo de tratamento de dados, seja realizado por pessoa natural ou jurídica, sendo impostas, consequentemente a todos os empregadores, com exceção dos empregadores domésticos, cuja aplicabilidade da Lei ainda gera divergências na doutrina ${ }^{14}$.

Assim sendo, a LGPD traz exigências específicas de acordo com a espécie de dado ou informação que o trabalhador está sujeito a disponibilizar, considerando cada cargo e

\footnotetext{
${ }^{14}$ ARAÚJO, Cristiane Carvalho Andrade. O impacto da LGPD nas relações de trabalho. 2020. Disponível em: https://www.conjur.com.br/2020-set-17/lgpd-impactos-trabalhistas. Acesso em: 21 jan. 2022.
} 
função em específico. Logo, a Lei também surge como norma complementar à CLT, no interesse de proteger as informações "doadas" pelo contratado ao contratante.

Em termos mais concretos, a LGPD fixa os moldes nos quais um empregador poderá ter acesso a dados pessoais e de trabalho de determinado funcionário a ele subordinado, ao mesmo passo que o limita na vistoria de todo e qualquer dado disponibilizado, dando certo resguardo de Direitos aos obreiros sujeitos à terem sua intimidade "vistoriada de maneira indiscriminada" pelo empregador, impondo ao empregador responsabilidade civil, uma vez que, desde a fase pré-contratual até o momento da rescisão do contrato de trabalho, o empregador é quem armazena, tem acesso e guarda os dados pessoais fornecidos pelos trabalhadores, responsabilidade essa que não se restringe à documentação pessoal de identificação dos trabalhadores, mas se estende ao monitoramento de correspondências eletrônicas, à captura de imagens dos trabalhadores no local de trabalho, às chamadas em sistemas de videoconferência, ao registro biométrico da jornada de trabalho, entre outros.

De forma mais suscinta, os dados do empregado são considerados como sensíveis, pois tratam de questões atravessadas por origem racial ou étnica, convicção religiosa, opinião política, filiação a sindicato ou a organização de caráter religioso, filosófico ou político, dado referente à saúde ou à vida sexual, dado genético ou biométrico.

Nesse sentido, embora a LGPD autorize as empresas a usar os dados pessoais dos seus empregados e prestadores de serviços (art. $7^{\circ}, \mathrm{V}$ e IX) para a legítima execução dos contratos, em benefício do próprio trabalhador, é necessário cautela e observância às regras da LGPD em todas as suas fases, nos atos praticados antes da contratação, durante a vigência do contrato, nas terceirizações e após a rescisão dos contratos.

Válido mencionar que, na terceirização de serviços, é preciso obter consentimento dos empregados por escrito para que a empresa faça o tratamento dos seus dados, sobretudo quando for transmiti-los a terceiros (tomadores de serviço), em decorrência da atividade realizada, ou mesmo por exigências legais e contratuais, especificando de maneira clara quais dados serão repassados e para qual finalidade.

Além do consentimento do empregado, é recomendável que as empresas criem obrigações específicas em seus contratos comerciais, de acordo com as exigências impostas pela LGPD no tratamento de dados.

Assim sendo, tem-se que os reflexos trazidos pela LGPD se fixam, em termos gerais, na garantia da proteção da Privacidade e Intimidade como Direitos Fundamentais, 
em face da descrição dos moldes a serem seguidos e respeitados pela classe empregatícia das relações de trabalho.

\section{LGPD, TELETRABALHO E A PANDEMIA DA COVID-19}

A princípio, como um dos maiores exemplos de garantia da proteção ao trabalhador, cuja função se encontra imersa no uso de plataformas digitais, tem-se o home office, sendo este uma espécie de trabalho cujo uso foi acentuado em decorrência das mudanças nas relações trabalho envolvidas na Pandemia da Covid-19 e priorização do isolamento social ${ }^{15}$.

No final do ano de 2019, a China enfrentava uma grave crise sanitária, ocasionada pelo surto de uma doença viral até então desconhecida. Posteriormente, o mundo tomou conhecimento de que se tratava de um novo Coronavírus humano, o SARS-CoV-2, causador da doença Covid-19.

Não é infundado afirmar que, como todas as demais áreas estruturais de quaisquer sociedades, o trabalho também foi diretamente afetado pela situação de pandemia. Na tentativa de conter o surto, atividades presenciais e não essenciais foram paralisadas e diversos direitos individuais foram limitados em decorrência da decretação de Estado de Calamidade Pública (Decreto Legislativo $\left.n^{\circ} 6 / 2020\right)^{16}$, o que impactou diretamente as relações de trabalho emprego e consequentemente a renda de diversas pessoas. Em meio a esse cenário caótico, o cotidiano do brasileiro foi substituído pelo "novo normal" e com ele houve um aumento significativo nas problemáticas enfrentadas no âmbito trabalhista no país.

Nesse contexto, a adoção do home office como o novo meio de continuidade das relações de emprego foi a única alternativa viável na tentativa de minimizar os impactos do quadro pandêmico na economia do país

Consequentemente, adentrando nos impactos da LGPD nas relações de trabalho em meio a pandemia, houve a ascensão da modalidade de trabalho a distância, o que

\footnotetext{
${ }^{15}$ BELMONTE, Alexandre Agra (coord.). Direito do Trabalho na crise da covid-19. Salvador, BA: Juspodivm, 2020. 816 p. Disponível em: https://especial.editorajuspodivm.com.br/ebook-direitotrabalho-covid19. Acesso em: 20 jan. 2022.

${ }^{16}$ BRASIL. Decreto $\mathbf{n}^{\mathbf{0}} \mathbf{6}$, de 2020. Brasília, 2020. Disponível em: http://www.planalto.gov.br/ccivil_03/portaria/DLG6-2020.htm. Acesso em: 3 jan. 2022.
} 
requer a elucidação de outro ponto importante da norma, qual seja os dois principais agentes envolvidos nessa cadeia de processos que culmina no tratamento de dados.

De acordo com a Lei, existem dois sujeitos distintos envolvidos diretamente vinculados à disponibilização e porte dos dados pessoais: Controlador, descrito no art. $5^{\circ}$, VI e o Operador, efetivado no art. 5, VII, LGPD.

Acerca do Controlador, este é pessoa física ou jurídica, de direito público ou privado, que detém o poder de decidir sobre como os dados pessoais serão tratados e para quais finalidades eles serão direcionados no processo interno da empresa. Já o Operador, é definido como a pessoa física ou jurídica, de direito público ou privado, que realiza o tratamento de dados de acordo com as orientações dadas pelo controlador. Em resumo, ambos são agentes responsáveis pelo tratamento das informações. O controlador está no topo da cadeia de tratamento de dados e a diferença entre eles está justamente no poder de decisão.

Como desdobramento de tais definições, havendo indícios de atos administrativos que ofendam a LGPD, é preciso, inicialmente, que se identifiquem os sujeitos envolvidos naquela infração, diferenciando o agente interno do - quando houver - agente externo, sendo o agente interno aquele que possui acesso aos dados por serem controladores, operadores ou encarregados. O agente externo, por sua vez, será aquele estranho à relação de tratamento de dados - como, por exemplo, um hacker, sendo que a LGPD abrange somente a atuação dos sujeitos internos, estando os agentes externos tipificados no Código Penal brasileiro e eventuais leis específicas.

Nesse sentido, a nova modalidade de teletrabalho não tinha muita expressividade no cenário empresarial e trabalhista brasileiro, não havendo um regramento bem estruturado para regular seu funcionamento. Pode-se afirmar que, essa forma de prestação de serviços é muito mais suscetível a falhas no processo de tratamento de dados, sendo assim, as empresas devem atentar-se aos seus profissionais que estão operando em regime home office, com possível acesso a dados pessoais e pessoais sensíveis, bem como às informações confidenciais da empresa ${ }^{17}$.

\footnotetext{
${ }^{17}$ CARLONI, Thais. A aplicação da LGPD na política de home office. 2020. Disponível em: https://monitormercantil.com.br/a-aplicacao-da-lgpd-na-politica-de-home-office/. Acesso em: 21 jan. 2022.
} 
Válido mencionar que, levantamento realizado pela empresa de consultoria BTA, realizado em $2020^{18}$, mostrou que, por decorrência da pandemia, o modelo de trabalho home office se tornou o padrão para ao menos $43 \%$ das empresas brasileiras, porcentagem que tende a aumentar, mesmo após o fim da pandemia, sendo necessário ajustes por parte das prestadoras de serviço, visando uma transição rápida e segura do antigo modelo para o novo, o que se mostra vantajoso, não só pela maior segurança, mas também por alavancar a credibilidade da empresa no mercado, assim como seu poder de competitividade. Sendo para tal, indispensável às implicações da LGPD nessas relações de trabalhos descriminadas.

Portanto, o acesso remoto ao servidor das empresas por meio de equipamentos particulares demanda esforço adicional para garantir o cumprimento da Lei, uma vez que requer a adoção de medidas técnicas e organizacionais para a proteção aos dados pessoais acessados remotamente sujeitos ao "firewall", dispositivos de segurança da rede que monitora o tráfego de entrada e saída e bloqueia tráfegos específicos de acordo com um conjunto definido de regras de segurança. Evidencia-se que, quando a empresa possui circulação de grande demanda de dados pessoais/sensíveis em geral na Área de Recursos Humanos, o risco é maior ainda, sendo imprescindível estabelecer alguns critérios, como: controlar o uso no home office, preferencialmente, tratando os dados em horário comercial ou até de forma mais restritiva, recomendar que revezem suas atividades entre home office e o próprio escritório.

Importante destacar ainda que, caso haja qualquer incidente de vazamento de dados decorrentes de conduta do Empregado no tratamento dos dados, em desconformidade com as orientações do Empregador, o Empregado poderá ser responsabilizado por tal incidente, devendo indenizar os prejuízos sofridos pelo Empregador e pelos titulares dos respectivos dados, na forma da lei.

Aliás, no que diz respeito às sanções administrativas por violação à "LGPD", é certo que as mesmas passarão a ser aplicadas somente a partir de agosto do ano de 2021, entretanto, é importante lembrar que existem outras ferramentas jurídicas que, desde já,

\footnotetext{
${ }^{18}$ BIGARELLI, Barbara. $43 \%$ das empresas adotam home office devido ao coronavírus: pesquisa com 359 companhias mostra que trabalho remoto é um desafio. Pesquisa com 359 companhias mostra que trabalho remoto é um desafio. 2020. Disponível em: https://valor.globo.com/carreira/noticia/2020/03/20/43percent-das-empresas-adotam-home-officedevido-ao-coronavirus.ghtml. Acesso em: 04 jan. 2021.
} 
podem ser utilizadas em face do infrator. A violação a qualquer obrigação legal pode gerar consequências jurídicas diversas da aplicação de sanções administrativas.

É certo que nesse período transicional para a economia e para o trabalho no país, a melhor forma de conduzir a situação é preparar os colaboradores, instruindo-os e treinando-os no que diz respeito ao dever de proteção dos dados pessoais, protegidos pelo sigilo e confidencialidade.

Assim sendo, tem-se que o aumento da demanda de trabalho à distância Decorrente da Pandemia da Covid-19 - e início da mobilização de empresas empregadoras para a adoção efetiva do home office como modalidade principal do exercício da função para a qual o trabalhador foi contratado, demanda, necessariamente, uma influencia da LGPD nos moldes em exercício dos empregadores. Desse modo, Direitos Fundamentais, tais como à Privacidade e Intimidade poderão ser preservados em meios virtuais.

\section{O CUMPRIMENTO EFETIVO DA LGPD: EXIGÊNCIAS APLICADAS AO AGENTE EMPREGADOR}

Como reflexo da vigência da LGPD, empresas e prestadores de serviços, independentemente de seu porte, quadro de funcionários, área de atuação ou faturamento, devem se adequar às novas previsões, sobretudo no que concerne aos dados pessoais e dados pessoais sensíveis, sobre os quais a Lei traz exigências que se mostram relevantes no âmbito das relações trabalhistas.

Nesse sentido, a norma traz a lógica da sanção responsiva ${ }^{19}$, onde a regra estabelece os parâmetros a serem adotados pelo empregador, visando à coleta, tratamento, armazenamento e descarte adequados dos dados pessoais dos trabalhadores, parâmetros que, uma vez descumpridos, geram a aplicação de uma sanção respectiva.

Assim sendo, em termos concretos, afirma-se que os impactos trazidos pela LGPD para as relações de emprego perpassam pela obrigatoriedade de análise minuciosa dos trâmites internos de coleta e tratamento de dados por parte dos empregadores, no intuito de garantir a adequação de seu respectivo sistema interno à legislação vigente, uma vez

${ }^{19}$ CRUZ, Camila. Punições da LGPD serão aplicadas a partir de agosto de 2021. 2021. Disponível em: https://mascaro.com.br/boletim/boletim-225/punicoes-da-lgpd-serao-aplicadas-a-partir-de-agosto-de2021/. Acesso em: 24 jan. 2022. 
que os ditames do dispositivo devem ser observados desde o processo seletivo para contratação de novo empregado, até após a dissolução do contrato de trabalho, imputando responsabilidade civil ao empregador desde o momento da captação dos dados ${ }^{20}$. No entanto, tendo em vista o grande fluxo de informações pessoais inerente aos vínculos laborais e frente à necessidade de armazenamento dos dados pessoais dos indivíduos contratados, tais exigências de conduta empregatícia resultam em novas responsabilidades para empresas de pequeno e grande porte.

Em resumo, a figura dos controladores e operadores assume o protagonismo, visto que ao controlador (empregador) compete as decisões relativas ao tratamento dos dados pessoais, enquanto ao operador (setor responsável pelo armazenamento de dados da empresa) cabe a realização efetiva desse tratamento, em nome do controlador.

Como desdobramento do recebimento das informações no exercício de seu objeto empresarial, o tratamento de dados passa a requerer o consentimento do titular (trabalhador) para ser realizado, e caso o receptor (empregador) necessite comunicar ou compartilhar dados com outros colaboradores, só poderá realizar a operação mediante consentimento específico, nos termos do art. $7^{\circ}$, I da Lei. Ademais, como complemento ao requisito do consentimento supracitado, a LGPD traz em seu escopo a possibilidade de trabalhadores questionarem seu respectivo empregador quanto ao tratamento dado aos seus dados pessoais, ensejando resposta no prazo de 15 (quinze) dias.

No que tange às denúncias por descumprimento da Lei no âmbito trabalhista, verifica-se que, em caso de violação às normas da LGPD, independente de já haver sido notificada a empresa responsável, poderá o titular/trabalhador ingressar com denúncia através do site da Autoridade Nacional de Proteção de Dados (ANPD), visto que a LGPD prevê que tal indivíduo possui o direito de peticionar em relação aos seus dados contra o controlador perante a autoridade nacional, vide art. 18, da LGPD.

De igual modo, a legislação impacta profundamente a forma de contratar e o procedimento de dispensa. Tais novos critérios tornam-se evidentes, ao citar, por exemplo, o tratamento diferenciado aplicado aos dados pessoais provenientes da contratação de pessoas menores de idade, pois há regras específicas para as crianças e

\footnotetext{
${ }^{20}$ NUNES, Daniele de Oliveira; OLIVIER, Nicolau. LGPD: a responsabilidade civil dos empregados enquanto envolvidos em operações de tratamento de dados. a responsabilidade civil dos empregados enquanto envolvidos em operações de tratamento de dados. Disponível em: https://www.migalhas.com.br/depeso/336154/lgpd--a-responsabilidade-civil-dos-empregados-enquantoenvolvidos-em-operacoes-de-tratamento-de-dados. Acesso em: 24 jan. 2022.
} 
adolescentes, consoante art. 14, Lei 13.709/2018, o qual determina a obrigatoriedade do consentimento específico assinado por pelo menos um dos pais ou pelo responsável legal, como requisito para contratação.

Quanto ao término do tratamento dos dados, seja pelo encerramento do contrato de trabalho/prestação de serviços em razão de dispensa ou por motivos alheios, os dados coletados/armazenados devem ser eliminados, restando autorizado o armazenamento com a finalidade de cumprimento de obrigação legal ou regulatória, ou seja, pelos prazos prescricionais legais. Logo, os dados coletados na fase pré-contratual, para fins de contratação, salvo consentimento específico do candidato, caso não seja contratado, devem ser eliminados, em consonância com os artigos 15 e 16, LGPD.

Ademais, como reflexos das exigências cabíveis às empregadoras, tem-se que ficou sob responsabilidade da classe empregatícia o cumprimento correto do prazo de guarda de dados pessoais, tendo em vista que a LGPD determina a eliminação destes logo após o término de seu tratamento, de acordo com seu art. 16. Entretanto, tal descarte de dados de forma imediata é prejudicial ao empregador, ao fundamento de que este se utiliza dos dados disponibilizados para resguardo nos casos de ajuizamento de reclamações trabalhistas ou da necessidade de prestar esclarecimentos previdenciários para a aposentadoria de ex-empregados.

Ainda, como controvérsia trazida pela nova legislação, que reflete nas relações laborais e obrigações dos empregadores, tem-se o uso do ponto eletrônico biométrico, considerado um dado pessoal sensível, de acordo com art. 5, II, LGPD. A norma determina que a coleta de biometria para uso do controle de ponto deve ser restrita às finalidades de controle de jornada e prevenção à fraude, sendo indicado, ainda, o uso de ferramentas de segurança mais rígidas como a criptografia, com vista a proteger esses dados sensíveis.

Nota-se que, as exigências impostas às empresas empregadoras, caso não regularmente executadas, geram como reflexo imediato o conflito de interesses entre empregador e empregado, o que de fato aumenta o número de demandas trabalhistas interpostas no judiciário trabalhista brasileiro. Inclusive, tal realidade ficou cabalmente demonstrada, mediante pesquisa realizada pelo DataLawyer a pedido do Jornal Valor ${ }^{21}$,

\footnotetext{
${ }^{21}$ ABATE, Sandra. Os impactos da LGPD nas relações de trabalho. 2021. Disponível em: https://www.migalhas.com.br/depeso/348538/os-impactos-da-lgpd-nas-relacoes-de-trabalho. Acesso em: 24 jan. 2022.
} 
a qual levantou cerca de 139 (cento e trinta e nove) ajuizamentos de ações trabalhistas questionando a LGPD nas relações de trabalho, reclamações estas que culminaram em valor total de $\mathrm{R} \$ 15.000 .000,00$ (quinze milhões de reais).

Evidencia-se, entretanto, que frente a todos os Direitos Fundamentais garantidos aos titulares dos dados pessoais tutelados pela Lei, é lógico deduzir que para cada proteção determinada, se fará necessária aplicação de sanção no caso de descumprimento, fato este que justifica o rol de penalidades e medidas coercitivas estipuladas nos arts. 52 a 54, da LGPD.

Dessa forma, ressalta-se que a má gestão empresarial pode impactar na inadequação do negócio à LGPD, gerando obrigação a danos morais e materiais trabalhistas, como resultado da violação ao Direito à Privacidade do empregado, incluindo-se ainda possíveis danos à imagem da empresa e fiscalização por parte do Ministério Público do Trabalho (MPT) ou pela Autoridade Nacional de Proteção de Dados (ANDP), que poderá impor as sanções disciplinares previstas no art. 52, I a XII, LGPD.

Em termos concretos, as sanções supracitadas somente serão aplicadas após procedimento administrativo que possibilite a oportunidade da ampla defesa de ambas as partes componentes da relação trabalhista contratual, de forma gradativa, isolada ou cumulativa. Ademais, estas se materializam na aplicação de advertências e multas simples ou multa diária, que variam de até $2 \%$ (dois por cento) do faturamento da empresa, limitada ao valor de $\mathrm{R} \$ 50.000 .000,00$ (cinquenta milhões de reais), publicização da infração, proibição do exercício de determinadas atividades, entre outros. No caso da aplicação de multa, evidencia-se que caso esta não seja quitada no prazo estabelecido, estará sujeito o empregador à inscrição em dívida ativa e execução fiscal pela União, com todas as consequências negativas conhecidas para os devedores de tributos federais. Aplicam-se, ainda, as sanções administrativas às pessoas físicas e jurídicas que estiverem em desacordo com os preceitos da Lei e a aplicação se concretizará por meio das decisões da Autoridade Nacional de Proteção de Dados, Órgão Federal vinculado ao Poder Executivo Federal.

Observa-se que, o valor arrecadado à título de multa ao descumpridor, não irá necessariamente para o ofendido, o qual teve seu dado violado indevidamente (trabalhador), o que recai em crítica por parte dos Doutrinadores quanto à LGPD. 
Nesse contexto, para resguardar a classe empregadora de possíveis medidas coercitivas pelo mau manuseio de dados de seus respectivos subordinados, aos agentes de tratamento cabe a adoção de medidas de segurança, técnicas e administrativas aptas a proteger os dados pessoais de acessos não autorizados e de situações acidentais ou ilícitas de destruição, perda, alteração, comunicação ou qualquer forma de tratamento inadequado ou ilícito.

Ante o exposto, esclarece-se que a LGPD não só estipula quais os moldes nos quais o Direito Fundamental à Privacidade deve ser assegurado, mas também exemplifica expressamente quais as medidas a serem adotadas, bem como as consequências e sanções por descumprimento, previstas para os casos de violação e inadimplemento por parte do empregador.

Desse modo, sejam quais forem as partes envolvidas na relação contratual, os Direitos à Privacidade e à Intimidade serão sempre objeto de proteção pela LGPD nas relações de Trabalho.

\section{CONSIDERAÇÕES FINAIS}

Ante o exposto, considerando os argumentos e fundamentos expostos, pode-se concluir que, a Lei Geral de Proteção de Dados Pessoais (Lei Federal nº 13.709, de 14 de agosto de 2018) tutela e protege as relações de dados e informações interpessoais em todo o cenário nacional.

Em uma análise primordial, entendia-se que a LGPD seria responsável por tutelar relações jurídicas de Direito do Consumidor e Direito Empresarial. No entanto, no decorrer da presente pesquisa, resta claro que a Lei se aplica também ao Direito do Trabalho, o qual é marcado por relações entre empregadores e empregados, atravessadas diretamente pela temática.

Contatou-se que o conflito de Direitos Fundamentais que a norma visa tutelar, encontra sua base na disponibilização desenfreada de dados e informações pessoais em meios predominantemente virtuais. Como resultado, Direito à Liberdade se contrapõe ao Direito à Privacidade; perpassou-se ainda por noções de priorização da proteção ao Direito à Intimidade, Privacidade, Honra e Imagem.

Fez-se ainda um apanhado histórico no ordenamento jurídico brasileiro, com a utilização de toda a legislação prévia à vigência da Lei 13.709/2018, a qual serviu como 
arcabouço para a criação das diretrizes concretas de proteção de dados no País, tais quais as Leis 8.078/90, 9.296/96, Lei Carolina Dieckman de 2012 e Lei n ${ }^{\circ}$ 12.965/14.

Em resumo, tais normas são englobadas nos preceitos da LGPD, que considerando o uso de plataformas virtuais pela sociedade pós Revolução Tecnológica 4.0, visa tutelar a disponibilização de dados e a possível violação à intimidade do trabalhador. Para tal, esclareceram-se as etapas que perpassam uma relação de trabalho, desde a aferição de dados pessoais, no momento de admissão, até o dia de dispensa ou finalização do contrato de trabalho.

Ademais, destacou-se que o aumento da demanda de trabalho na modalidade home office - Decorrente da Pandemia da Covid-19 -, determinou, obrigatoriamente, a incidência da LGPD como norteadora das relações de trabalho, ao passo que, para exercer sua função, o trabalhador tem, como requisito prévio, a disponibilização de seus dados. Desse modo, Direitos Fundamentais como Privacidade e Intimidade precisam ser analisados com maior cautela.

Evidenciou-se ainda, que a LGPD, além de determinar os tipos de dados a serem tutelados, assim como os tipos de agentes presentes nas ações de disponibilização de dados, ainda traz em seu conteúdo as exigências e sanções a serem aplicadas em casos de quebra de norma nela contida, por parte dos empregadores.

Assim sendo, pode-se concluir que a LGPD gerou reflexos no âmbito do Direito do Trabalho, ao proteger os Direitos Fundamentais à Liberdade e à Privacidade do trabalhador, ao mesmo tempo em que determinou de que formas os empregadores poderiam ter acesso às informações sensíveis por eles disponibilizadas, e quais os moldes para o seu armazenamento correto.

\section{REFERÊNCIAS}

ABATE, Sandra. Os impactos da LGPD nas relações de trabalho. 2021. Disponível em: https://www.migalhas.com.br/depeso/348538/os-impactos-da-lgpd-nas-relacoes-detrabalho. Acesso em: 24 jan. 2022.

AIPP, (International Association Of Privacy Professionals). O Que Muda com a Nova Lei de Dados Pessoais: lei federal 13.709/18. Lei Federal 13.709/18. 2018. Disponível em: https://www.lgpdbrasil.com.br/o-que-muda-com-a-lei/. Acesso em: 17 jan. 2022.

ARAÚJO, Cristiane Carvalho Andrade. O impacto da LGPD nas relações de trabalho. 2020. Disponível em: https://www.conjur.com.br/2020-set-17/lgpd-impactostrabalhistas. Acesso em: 21 jan. 2022. 
BELMONTE, Alexandre Agra (coord.). Direito do Trabalho na crise da covid-19. Salvador, BA: Juspodivm, 2020. 816 p. Disponível em:

https://especial.editorajuspodivm.com.br/ebook-direito-trabalho-covid19. Acesso em: 20 jan. 2022.

BIGARELLI, Barbara. $43 \%$ das empresas adotam home office devido ao coronavírus: pesquisa com 359 companhias mostra que trabalho remoto é um desafio. Pesquisa com 359 companhias mostra que trabalho remoto é um desafio. 2020. Disponível em: https://valor.globo.com/carreira/noticia/2020/03/20/43percent-dasempresas-adotam-home-office-devido-ao-coronavirus.ghtml. Acesso em: 04 jan. 2021.

BLUM, Renato Opice; WAJSBROT, Shirly. A proteção de dados no Brasil 4.0. 2020. Disponível em: https://institutoibde.com.br/2020/06/26/a-protecao-de-dados-no-brasil4-0/. Acesso em: 22 jan. 2022.

BRASIL. Constituição (1988). Constituição Federal, de 1988. Brasília, DF, 1988. Disponível em: http://www.planalto.gov.br/ccivil_03/constituicao/constituicao.htm. Acesso em: 10 jan. 2022.

BRASIL. Decreto no 6, de 2020. Brasília, 2020. Disponível em: http://www.planalto.gov.br/ccivil_03/portaria/DLG6-2020.htm. Acesso em: 3 jan. 2022.

BRASIL. Lei no 8.078, de 1990. Brasília. Disponível em: http://www.planalto.gov.br/ccivil_03/leis/18078compilado.htm. Acesso em: 05 jan. 2022

BRASIL. Lei no 9.296, de 24 de julho de 1996. Brasília, Disponível em: http://www.planalto.gov.br/ccivil_03/leis/19296.htm. Acesso em: 05 jan. 2022.

BRASIL. Lei no 12.737, de 2012. Lei Carolina Dieckman. Disponível em: http://www.planalto.gov.br/ccivil_03/_ato2011-2014/2012/lei/112737.htm. Acesso em: 20 jan. 2022.

BRASIL. Lei no 12.965, de 2014. Brasília, Disponível em: http://www.planalto.gov.br/ccivil_03/_ato2011-2014/2014/lei/112965.htm. Acesso em: 07 jan. 2022.

BRASIL. Lei $\mathbf{n}^{\mathbf{0}}$ 13.709, de 14 de julho de 2018. Lei Geral de Proteção de Dados Pessoais (LGPD). Brasília, DF, Disponível em: http://www.planalto.gov.br/ccivil_03/_ato2015-2018/2018/lei/113709.htm. Acesso em: 10 jan. 2022.

CANTELMO, Fernando. A Lei Geral de Proteção de Dados e o conflito entre direito de privacidade versus direito de informação e publicidade dos atos públicos: noções legais sobre divergências constitucionais consolidadas pela lgpd. Noções legais sobre divergências constitucionais consolidadas pela LGPD. 2021. Disponível em: https://jus.com.br/artigos/92061/a-lei-geral-de-protecao-de-dados-e-o-conflito-entredireito-de-privacidade-versus-direito-de-informacao-e-publicidade-dos-atos-publicos. Acesso em: 19 jan. 2022. 
CARLONI, Thais. A aplicação da LGPD na política de home office. 2020.

Disponível em: https://monitormercantil.com.br/a-aplicacao-da-lgpd-na-politica-dehome-office/. Acesso em: 21 jan. 2022.

CRUZ, Camila. Punições da LGPD serão aplicadas a partir de agosto de 2021. 2021. Disponível em: https://mascaro.com.br/boletim/boletim-225/punicoes-da-lgpdserao-aplicadas-a-partir-de-agosto-de-2021/. Acesso em: 24 jan. 2022.

DELGADO, Mauricio Godinho. Curso de Direito do Trabalho. 8. ed. São Paulo/sp: Ltr, 2009.

LIMA, Gabriela Vasconcelos; FEITOSA, Gustavo Raposo Pereira. Online dispute resolution (ODR): a solução de conflitos e as novas tecnologias. Revista do Direito, Santa Cruz do Sul, v. 3, n. 50, p. 53-70, jan. 2016. ISSN 1982- 9957.Disponível em: https://online.unisc.br/seer/index.php/direito/article/view/8360. Acesso em: 17 jan. 2022.

MACIEL, Rafael Fernandes. Manual Prático sobre a Lei Geral de Proteção de Dados Pessoais (Lei no 13.709/18). RM Digital Education. $1^{\text {a }}$ Edição. Goiânia - GO. 2019.

MARCHI, Caroline; ASSALIN, Fernanda Pellegrino Gianotti. Implicações dos algoritmos nas relações de trabalho após a LGPD. 2021. Disponível em: https://www.machadomeyer.com.br/pt/inteligencia-juridica/publicacoes-ij/trabalhistaij/implicacoes-dos-algoritmos-nas-relacoes-de-trabalho-apos-a-lgpd. Acesso em: 23 jan. 2022.

NUNES, Daniele de Oliveira; OLIVIER, Nicolau. LGPD: a responsabilidade civil dos empregados enquanto envolvidos em operações de tratamento de dados. a responsabilidade civil dos empregados enquanto envolvidos em operações de tratamento de dados. Disponível em:

https://www.migalhas.com.br/depeso/336154/lgpd--a-responsabilidade-civil-dosempregados-enquanto-envolvidos-em-operacoes-de-tratamento-de-dados. Acesso em: 24 jan. 2022.

SOARES, Paulo Vinicius de Carvalho. Guia LGPD: lei geral de proteção de dados simplificada. Lei Geral de Proteção de dados Simplificada. 2020. Disponível em: https://d335luupugsy2.cloudfront.net/cms/files/92859/1565723282Guia_-_LGPD.pdf. Acesso em: 12 jan. 2022.

Recebido em: 20/01/2022

Aprovado em: 21/02/2022

Publicado em: 24/02/2022 